\title{
O Direito à Participação Política das Pessoas com Deficiência
}

\author{
The Right to Political Participation of Persons with Disabilities
}

Joelson Dias

Ana Luísa Cellular Junqueira

Resumo: Por ser elemento precípuo na conformação do interesse público, a participação do indivíduo na tomada de decisões políticas está intimamente conectada com a soberania popular. A abertura de canais para o povo opinar e participar transforma o indivíduo subserviente em cidadão ativo, com poder de influenciar de fato as decisões tomadas em seu nome. A garantia ao sufrágio e suas manifestações reclama, dessa forma, a eliminação de obstáculos (atitudinais, físicos e socioeconômicos) limitantes ou demasiadamente onerosos, que impedem os grupos mais vulneráveis expressarem seu potencial político. É precisamente nesse contexto que surgem as normas destinadas a promover a voz cidadã das pessoas com deficiência.

Palavras-chave: Pessoas com deficiência. Participação política. Convenção Internacional da ONU sobre os Direitos das Pessoas com Deficiência. Lei Brasileira de Inclusão.

\begin{abstract}
The participation of individuals in political decision-making is a key element in shaping public interest and is therefore closely connected to popular sovereignty. The opening of new communication channels for people to give their opinions and participate in discussions has transformed the subservient individual into an active citizen with the power to indeed influence the decisions being made on his behalf. The guarantee of the right to vote and such related rights demands, therefore, the elimination of obstacles (attitudinal, physical and socioeconomic) that impede, constrain or, most seriously, prevent the most vulnerable groups from expressing their political rights. It is precisely in this context that standards are emerging which are designed to enable people with disabilities to use their 'voice' as a citizen.
\end{abstract}

Keywords: Persons with disabilities. Political participation. UN International Convention on the Rights of Persons with Disabilities. Brazilian Inclusion Law.

Artigo recebido em 31 ago. 2017 e aprovado em 21 set. 2017. 


\section{Introdução}

Embora a concepção de soberania popular advenha dos ideais sustentados pela Revolução Francesa (1789-1799), a participação do povo nos mecanismos públicos de tomada de decisão, de definição/execução de políticas públicas e de controle da gestão administrativa ainda está distante de atingir sua plenitude. No mundo ocidental, as oportunidades para a atuação do indivíduo na esfera pública foram gradualmente se incrementando a partir do final do século XVIII, período inicial do movimento de incorporação das enunciações dos direitos humanos no texto das constituições nacionais.

Com a consolidação do Estado Democrático de Direito, a dignidade humana transformou-se em axioma universal de toda e qualquer função pública. Por ser agente precípuo na consolidação do interesse público, a participação política na condução do Estado torna-se direito fundamental e pressuposto da soberania popular.

Em que pese a imprescindibilidade de se assegurar ao indivíduo liberdade para discutir publicamente suas reivindicações, em uma ordem democrática as decisões públicas só podem ser consideradas legítimas se o acesso à participação na esfera política também for garantido a todos de forma igualitária.

Nas palavras de Rousseau (1980 apud ADRIOLI, 2003), não existe liberdade sem igualdade. O ser humano em condição superior terá sempre mais poder, limitando os outros em situação inferior. A justiça social será alcançada apenas quando a liberdade for concedida na mais perfeita igualdade.

$\mathrm{Na}$ construção de um Estado que se oponha à sociedade corrompida pela desigualdade, afastando os obstáculos que oneram ou impedem que os grupos excluídos tenham voz ativa, as chances para o desenvolvimento de capacidades ${ }^{1}$ individuais se multiplicam. Existe estreita conexão entre expressão da vontade política e os demais direitos fundamentais. Isso se deve ao fato de que o indivíduo, ao participar ativamente na esfera pública, interfere na construção e na legitimação de suas outras garantias fundamentais: civis, econômicas, sociais e culturais.

\footnotetext{
${ }^{1}$ Adotando a linha de pensamento de Amartya Sen, "capacidade" representa série de combinações alternativas de estados físicos e mentais que uma pessoa é capaz de fazer, de se tornar ou de ser. São oportunidades ou liberdades para alcançar aquilo que um indivíduo considera valioso. (SEN, Amartya. A ideia de justiça. São Paulo: Companhia das Letras, 2011).
} 
É precisamente nesse contexto que surge a preocupação em garantir acessibilidade política às pessoas com deficiência, com a eliminação dos obstáculos impeditivos ou a criação das condições necessárias à efetivação dos seus direitos. A participação política é enérgico instrumento que assegura a convivência social efetivamente inclusiva, justa e solidária.

\section{Igualdade de Oportunidades na Participação Política como Substrato da Democracia}

Em que pese o fato do exercício ao sufrágio ${ }^{2}$ ser a pedra angular do direito à participação política, não devemos desconsiderar suas outras múltiplas manifestações que se expressam pelo direito à associação e reunião, ao pluralismo político, ao voto regular e universal, à militância partidária, à presença em manifestações, à pressão exercida sobre governantes, à difusão de informações políticas e discussão sobre temas públicos.

Em outros termos: direitos políticos são os meios necessários ao exercício da soberania popular. São os direitos à cidadania, garantidores da participação ativa do indivíduo nas funções do Estado, por isso, são também considerados como um dos substratos da democracia, já que não existe democracia sem participação popular. Daí a razão dos direitos políticos serem considerados fundamentais.

A expressão política do indivíduo fundamenta a democracia na medida em que lhe confere legitimidade. Não existe regime democrático onde a coletividade - ou parte significativa dela, como os grupos social, econômica ou culturalmente vulneráveis - esteja alijada das esferas onde se forjam o debate e as orientações de caráter público, porque, como enfatiza Urroz (2011, p. 83), a democracia caracteriza-se como o regime no qual as decisões fundamentais defluem de todos os cidadãos e cidadãs. ${ }^{3}$

\footnotetext{
${ }^{2} \mathrm{O}$ direito ao sufrágio envolve dupla dimensão: o direito de sufrágio ativo (direito do cidadão eleger representantes dos poderes Executivo e Legislativo, ou opinar sobre políticas públicas) e o de sufrágio passivo (prerrogativa de se apresentar como candidato durante o processo eleitoral).

${ }^{3}$ Embora as normas de linguagem recomendem a adoção do "masculino extensivo", nos casos que o gênero gramatical masculino se junta a um feminino, usaremos neste texto não só a expressão "cidadãos", como também "cidadãs", e outras afins, no deliberado propósito de reforçar a linguagem inclusiva, combatendo estereótipos e o modelo predominante em que o homem se torna a medida do humano, a norma ou o padrão. O direito à representação linguística pressupõe um direito à identidade, sendo condição necessária para tornar real e efetiva a igualdade entre homens e mulheres.
}

Resenha Eleitoral (Florianópolis), v. 21, n. 1, p. 159-180, nov. 2017 
Nesse aspecto, a abertura de canais para o exercício dos direitos políticos, além de tornar o ambiente social mais plural e em conformidade com a justiça social, transforma o indivíduo subserviente em cidadão ativo, com poder de influenciar de fato as decisões políticas tomadas em seu nome. Há, assim, um ciclo virtuoso entre direitos políticos, cidadania e democracia. Por intermédio da participação, o indivíduo se fortalece como cidadão e, mais fortalecido, participa cada vez mais, solidificando a cultura democrática e concretizando o Estado Democrático de Direito. Mas não é só.

Não obstante a liberdade de participação seja um dos pilares democráticos, a vontade política só será legítima se todos puderem exercer seu direito de sufrágio em igualdade de oportunidades. Uma sociedade livre da opressão e da submissão deve, obrigatoriamente, considerar a participação política em dimensão equânime e inclusiva.

Garantir meios que igualem as oportunidades de acesso às liberdades individuais é contribuir para a radicalização democrática, emancipação e mudança social. A liberdade de se expressar politicamente é por si um valor essencial, mas deve ser garantida de forma igual a todos para que seja alcançada a justiça social.

Como aponta Della Porta (2003 apud ALVIM; DIAS, no prelo), a democracia tem amparo na isonomia e, assim, refuta desigualdades nas medidas da participação, porquanto ensejam desequilíbrios na influência política dos diferentes sujeitos e classes. $\mathrm{O}$ alijamento político de grupos não centrais - como é o caso das pessoas com deficiência - produz distorções no esquema público de distribuição de justiça, tanto porque embaraça a impressão de seus esforços sociais como porque dificulta a sua mobilização em outros níveis.

Para Rawls (1995, p. 266, tradução nossa), a desigualdade política mais óbvia talvez se exprima na violação do preceito "uma pessoa, um voto". Na formulação de sua "Teoria de Justiça", anuncia que o princípio de (igual) participação, quando aplicado ao processo político, exige que todos os cidadãos devem ter acesso igual ao poder público: "a justiça como imparcialidade começa com a ideia de que, se os princípios gerais são necessários e vantajosos para todos, devem ser elaborados desde o ponto de vista de uma situação inicial de igualdade bem definida, onde cada pessoa está justamente representada.".

$\mathrm{Na}$ tentativa de formular um modelo político mais justo ou adequado à complexidade das sociedades contemporâneas, Habermas (2002) 
entende que a exclusão do "diferente" se dá por meio de uma vontade consciente de homogeneidade social, que provoca a marginalização interna de grupos sociais. Sua proposta contra essa exclusão sistemática consiste na defesa de que a política própria da democracia deve ser dirigida na direção da "inclusão do outro", uma inclusão que promova a independência de características individuais de cada qual, e que conte com acesso à comunidade política. A condição para isso é que, no maior grau possível, as instituições públicas se dispam de conotações morais densas, e passem a adotar integralmente os procedimentos do direito moderno.

A rigor, como ensina Pateman (1992, p. 41), um sistema realmente democrático deve favorecer a máxima implicação dos cidadãos e cidadãs na definição das leis e no delineamento das políticas: em seu ambiente, o processo participativo deve assegurar que nenhum indivíduo ou grupo esteja acima de outros indivíduos ou grupos; as camadas sociais são dependentes entre si e, desse modo, devem igualmente ser abrigadas pelo sistema legal.

Por sua própria condição, determinados indivíduos necessitam de proteção específica, indispensável para que possam se incluir socialmente e participarem em condições de igualdade. Para que seja atingida integralmente a igualdade, devemos considerá-la em sua dimensão material.

Como aponta Silva (2001), em sociedades corrompidas pela desigualdade, a norma geral aplicada igualmente a todos (igualdade formal) pode gerar injustiças sociais, já que as desigualdades reais não deixarão de existir. Deve-se então, levar em conta as distinções dos grupos sociais (igualdade material), pois, ao contrário, o direito acaba por gerar mais desigualdades. Em outras palavras, o tratamento desigual aos grupos socialmente mais vulneráveis é essencial para se garantir a igualdade na realidade fática da vida. É a chamada "desigualação" positiva, desigualando para igualar. Ademais, a noção de povo como "a razão e fim da sociedade e Estado" deve ser compreendida com base na diversidade humana, respeitando e aceitando as diferenças entre os indivíduos.

Essa é razão das normas que garantem a acessibilidade e o próprio direito à participação política das pessoas com deficiência. A garantia de que esse grupo específico de pessoas possa intervir nas decisões do Estado, especialmente nas questões que lhe dizem respeito mais diretamente, revela-se elemento crucial na construção e promoção de sua inclusão social. 
Até porque, existe uma conexão íntima entre o direito de participação política e os demais direitos essenciais para a preservação da dignidade humana. Afinal, ao participar ativamente na esfera pública, o indivíduo interfere na construção e legitimação de seus outros direitos fundamentais: civis, econômicos, sociais e culturais. É, assim, agente de transformação social, incluindo e emancipando grupo socialmente mais vulnerável.

\section{Acessibilidade Eleitoral da Pessoa com Deficiência: normas de proteção e promoção}

Segundo dados do Relatório Mundial de 2011 sobre as pessoas com deficiência, elaborado pela Organização Mundial de Saúde, mais de um bilhão de pessoas no mundo convivem com alguma forma de deficiência (física, mental, intelectual ou sensorial), dentre as quais, 200 milhões experimentam dificuldades funcionais consideráveis. Só no Brasil, quase $24 \%$ da população apresenta algum tipo de deficiência. No grupo socialmente vulnerável, existem, atualmente, milhões de pessoas que deixam de exercer seus direitos de participação nas atividades do Estado por não terem acesso aos meios viabilizadores.

O direito à acessibilidade é compreendido como o direito de ter acesso a direitos. É, portanto, instrumento fundamental para a efetivação dos demais direitos, por isso, há uma relação entre dignidade humana e direito à acessibilidade. A pessoa com deficiência somente poderá usufruir de uma vida digna, caso tenha garantido acesso aos direitos fundamentais.

A acessibilidade eleitoral visa erradicar as barreiras que distanciam os indivíduos do exercício de seus direitos políticos. Não se traduz exclusivamente no direito de votar com facilidade, vai além. Tem como propósito a superação, dentre outros, dos obstáculos arquitetônicos das zonas e seções eleitorais; do preconceito e ignorância social que mitigam as chances de candidatos e candidatas com deficiência serem eleitos; da inacessibilidade das propagandas partidárias e eleitorais, dos informes oficiais e debates televisivos que não contam com audiodescrição, linguagem de sinais e legenda.

A garantia ao sufrágio e às suas manifestações reclama, dessa forma, a eliminação de obstáculos (atitudinais, físicos e socioeconômicos) impeditivos ou demasiadamente onerosos, que limitam principalmente os grupos mais vulneráveis de expressarem seu potencial político. Nessa linha, Dahl (2009 apud ALVIM; DIAS, no prelo) alerta que o axioma da máxima 
extensão do sufrágio não se esgota no amplo reconhecimento formal do direito ao voto, pois a satisfação das exigências democráticas pressupõe que "os direitos nela inerentes devem realmente ser cumpridos e, na prática, devem estar à disposição dos cidadãos".

\subsection{Normas Internacionais de Direitos Humanos que Assegu- ram Acessibilidade Eleitoral da Pessoa com Deficiência}

No sistema global de proteção dos direitos humanos, a Convenção da Organização das Nações Unidas (ONU) sobre os Direitos das Pessoas com Deficiência (CDPD) - primeiro Tratado Internacional de Direitos Humanos incorporado ao ordenamento jurídico nacional com equivalência expressa de norma constitucional $-{ }^{4}$, surge não apenas como oportuno instrumento de efetivação dos mais variados direitos e garantias, mas como marco normativo revolucionário, que conduz a legislação e as instituições eleitorais ao reencontro com os valores democráticos de inclusão e justiça social.

Em termos gerais, a CDPD traduz-se como importante mecanismo de alcance global para modificar o cenário de exclusão das pessoas com deficiência nos países signatários, destacando as vulnerabilidades enfrentadas pelos beneficiários, e exigindo das autoridades nacionais e dos diversos atores sociais ações concretas para a implementação dos direitos e garantias consagrados em seu texto. A Convenção foi adotada pela Comunidade Internacional com o propósito estruturante de assegurar e promover a emancipação das pessoas com deficiência, principalmente, a partir do princípio da igualdade e da inclusão social, o qual se desdobra no direito à promoção de acessibilidade aos direitos humanos e fundamentais.

\footnotetext{
${ }^{4}$ Mediante o Decreto Legislativo no 186 , de 9 de julho de 2008, promulgado pelo Poder Executivo federal por meio do Decreto n⿳⺈ 6.949, de 25 de agosto de 2009, o Congresso Nacional aprovou o texto da Convenção da ONU sobre os Direitos das Pessoas com Deficiência, bem assim seu Protocolo Facultativo, que reconhece a competência do Comitê sobre os Direitos das Pessoas com Deficiência para receber e analisar comunicações submetidas por pessoas ou grupos de pessoas narrando violações ao referido tratado internacional. Além do compromisso junto à ONU firmado pela União valer para todos os entes da Federação e para os três Poderes, o texto da Convenção constitui parâmetro de controle de constitucionalidade, sendo que a não observância de seus preceitos enseja mora internacional do Estado brasileiro. Ao Executivo cabe a implementação de medidas necessárias ao cumprimento das obrigações previstas; ao Legislativo, compatibilizar a legislação com os novos compromissos; e ao Judiciário, aplicar e assegurar a obediência ao tratado, conforme o seu status de emenda constitucional.
} 
Como afirma Caldas (2014), a CDPD prevê verdadeiras regras de conduta para os Estados, os quais assumem a responsabilidade de, internamente, implementar as normas internacionais criadas pela Convenção, adequando a legislação interna e criando políticas capazes de intervir na realidade e modificá-la, ao propagar informação, disseminar tecnologias, e assegurar o acesso das pessoas com deficiência aos direitos à educação, saúde e acessibilidade, integrando-as à sociedade.

Em seu art. 1ํa CDPD define pessoa com deficiência como aquela com impedimentos de longo prazo de natureza física, mental, intelectual ou sensorial, os quais, em interação com diversas barreiras (físicas, atitudinais, socioeconômicas) podem obstruir sua participação plena e efetiva na sociedade, em igualdade de condições com as demais pessoas ${ }^{5}$.

Nota-se relevante mudança de paradigma sobre a definição de pessoa com deficiência, afastando de vez o modelo médico do referido conceito. A deficiência deixa de ser tratada como uma limitação do corpo, e passa a ser encarada como construção social e questão contextual.

A pessoa com deficiência apresenta maior dificuldade de acesso não em razão de suas limitações funcionais, mas pela incapacidade da sociedade de incluí-la em sua especificidade. Assim, a limitação funcional do indivíduo deixa de ser um obstáculo quando apoiada pelos recursos de acessibilidade promovidos pelo Estado e pela sociedade, e garantida à pessoa com deficiência a sua inclusão, autonomia e vida independente.

Capítulo especial da Convenção da ONU foi dedicado aos direitos e garantias de participação na vida pública e política das pessoas com deficiência, com o propósito de assegurar sua inclusão política, amortizando, assim, dívida do sistema com a dignidade humana, e revigorando o substrato democrático do estatuto eleitoral. Ao assinar e depois incorporar em seu direito interno como norma constitucional a CDPD, o Brasil assumiu o ônus de adotar medidas necessárias para garantir e promover também a acessibilidade política e eleitoral das pessoas com deficiência ${ }^{6}$.

\footnotetext{
${ }^{5}$ O propósito da presente Convenção é promover, proteger e assegurar o exercício pleno e equitativo de todos os direitos humanos e liberdades fundamentais por todas as pessoas com deficiência, e promover o respeito pela sua dignidade inerente. Pessoas com deficiência são aquelas que têm impedimentos de longo prazo de natureza física, mental, intelectual ou sensorial, os quais, em interação com diversas barreiras, podem obstruir sua participação plena e efetiva na sociedade em igualdade de condições com as demais pessoas.
}

${ }^{6}$ Vide art. 4.1, $a$, da CDPD. 
Em seu art. 29, a CDPD estabelece que os Estados Partes deverão comprometer-se a assegurar o direito das pessoas com deficiência votarem e serem votadas em condições de igualdade com as demais pessoas. Para isso, determina que os procedimentos, instalações e materiais, e equipamentos para votação serão apropriados, acessíveis, e de fácil compreensão e uso, assegurando a proteção ao voto secreto, e garantindo-se, sempre que necessário e a seu pedido, permissão para que a pessoa com deficiência seja auxiliada na votação por alguém de sua escolha. Assegura também o direito das pessoas com deficiência candidatarem-se e desempenharem quaisquer funções públicas em todas as esferas de governo, usando novas tecnológicas assistivas quando apropriado.

Em acréscimo, a CDPD encoraja a promoção de ambiente no qual as pessoas com deficiência possam participar efetiva e plenamente na condução das questões públicas, mediante filiação a organizações não governamentais relacionadas com a vida pública e política do país, e a formação de organizações (em âmbito internacional, regional, nacional e local) que representem seus interesses.

No sistema Regional Interamericano de Direitos Humanos, a proteção normativa especial das pessoas com deficiência está prevista no texto da Convenção Interamericana para a Eliminação de Todas as Formas de Discriminação contra as Pessoas com Deficiência da Organização dos Estados Americanos (Convenção da Guatemala). Embora não contemple artigo específico sobre os direitos políticos, referida Convenção obriga a adoção pelos países signatários de medidas de natureza legislativa, social, educativa, laboral ou outra que sejam necessárias para eliminar a discriminação contra as pessoas com deficiência.

No sistema europeu de direitos humanos, a Carta dos Direitos Fundamentais da União Europeia prescreve que os Estados-Membros devem reconhecer e respeitar o direito das pessoas com deficiência, a se beneficiarem de medidas destinadas a assegurar a sua autonomia, a sua integração social e a sua participação na vida da comunidade.

No mesmo sentido, a Recomendação (2006)5, de 5 de abril de 2006, do Comitê de Ministros aos Estados-Membros, sobre o Plano de Ação do Conselho da Europa para promover os direitos das pessoas com deficiência, defende que a participação de todos os cidadãos na vida política 
e pública, e no processo democrático, é fundamental para o desenvolvimento das sociedades democráticas ${ }^{7}$.

Em adição, a Recomendação (2004)10, de 22 de setembro de 2004, do Comitê de Ministros aos Estados-Membros, sobre a proteção dos direitos humanos e da dignidade das pessoas com transtornos mentais, sugere que referidos indivíduos devem poder exercer todos os seus direitos civis e políticos. A justificativa é que quaisquer restrições ao exercício desses direitos devem observar as disposições da Convenção Europeia para a Proteção dos Direitos do Homem e das Liberdades Fundamentais, e não devem se basear em discriminação de pessoa com transtorno mental.

\subsection{Lei Brasileira de Inclusão e o Programa de Acessibilidade da Justiça Eleitoral}

Para lidar adequadamente com os ditames da Convenção da ONU, foi promulgada no Brasil, em 6 de julho de 2015, a Lei no 13.146 (Lei Brasileira de Inclusão da Pessoa com Deficiência - LBI), também conhecida como Estatuto da Pessoa com Deficiência.

Após praticamente 15 anos de tramitação no Congresso e várias revisões, modificações, audiências públicas e estudos, a LBI foi aprovada com grande expectativa de que possa ser usada como importante instrumento para a afirmação da cidadania e a inclusão social das pessoas com deficiência, indo ao encontro, assim, das obrigações internacionais assumidas pelo País ao ratificar a Convenção Internacional da $\mathrm{ONU}^{8}$.

${ }^{7}$ De acordo com a Recomendação (2006)5, de 5 de abril de 2006, emitida pelo Comitê de Ministros aos Estados-Membros sobre o Plano de Ação do Conselho da Europa para promover os direitos das pessoas com deficiência: "A participação de todos os cidadãos e cidadãs na vida política e pública e no processo democrático é fundamental para o desenvolvimento das sociedades democráticas. A sociedade tem necessidade de refletir sobre a diversidade dos seus eleis e de tirar benefício da variedade da sua experiência e conhecimento/saber. Assim, é importante que as pessoas com deficiência/incapacidade possam exercer o seu direito de voto e de participar em tais atividades." Disponível em: www. inr.pt/uploads/docs/relacoesinternacionais/planoaccaofinal.rtf, acesso em: 14 de out. de 2017

${ }^{8}$ Embora grande parte dos organismos representativos e do poder público tenha defendido que a reunião dos direitos das pessoas com deficiência em um só instrumento jurídico facilitaria as decisões judiciais, bem como ampliaria a sua visibilidade, importante lembrar que número expressivo de pessoas do próprio segmento mostrou-se contrário à aprovação de um "Estatuto". Temendo que lei especial sobre o tema pudesse derrogar alguns dos direitos garantidos pela legislação então em vigor, essa corrente defendia não ser preciso 
Com a LBI, mais precisamente por força do disposto em seu artigo 114, a incapacidade civil absoluta, prevista como causa de restrição de direitos políticos, no inciso II do art. 15 da Constituição Federal, foi reduzida a uma única hipótese, a dos menores de 16 anos, com a nova redação dada ao art. 3º, do Código Civil, assegurando, a partir de então, capacidade política também aos indivíduos com deficiência intelectual ou mental. Com efeito, no $\$ 1^{\circ}$ do seu artigo 76 a LBI garante às pessoas com deficiência não apenas o direito de voto, mas também o de serem votadas.

No que se refere às garantias destinadas à participação na vida pública e política das pessoas com deficiência, a LBI (art. 76) basicamente reproduz a redação da Convenção da ONU (art. 29), incorporando no texto, todavia, algumas medidas adicionais para a efetivação do referido direito.

Seguindo a Convenção, a LBI visa garantir às pessoas com deficiência o exercício dos direitos políticos e a oportunidade de exercê-los em igualdade de condições com os demais indivíduos, inovando ao vedar expressamente seções eleitorais exclusivas para as pessoas com deficiência. Ressalte-se, por oportuno, que o TSE somente poderá continuar estabelecendo "seções eleitorais especiais" ${ }^{9}$ se não forem exclusivas para os eleitores e eleitoras com deficiência e, sem prejuízo, é claro, de garantia da acessibilidade de todo e qualquer local de votação.

Nesse ponto em que segue a Convenção da ONU, o objetivo da LBI é não somente o de evitar a segregação das pessoas com deficiência e preservar o seu direito ao sigilo do voto, mas também, considerando que a maioria dos locais de votação é localizada em edifícios públicos, promover a acessibilidade dos prédios públicos ou de uso coletivo, e de suas imediações ${ }^{10}$. Com efeito,

remodelagem legislativa, tendo em vista que o sistema jurídico brasileiro de proteção aos direitos das pessoas com deficiência é dos mais avançados do mundo. Além do mais, no inciso I de seu artigo 14, a LC n⿳0 95/98 prevê expressamente não ser o caso da edição de nova lei, mas de consolidação da legislação sempre que já existentes normas que tratem da mesma matéria ou de assuntos a ela vinculados.

${ }^{9}$ Ver, por exemplo, Resolução TSE n⿳丷ㅡㄹ 21.008/2002 (art. 1º) e Resolução TSE nº 23.381/12 (art. 3을 III e IV).

${ }^{10}$ Vide, ainda, o disposto no art. 21, parágrafo único, do Decreto ํㅡㄴ 5296/2004, que dispõe sobre a acessibilidade nos prédios de uso coletivo e público para as pessoas com deficiência ou mobilidade reduzida. 
a LBI incluiu o $\int 6^{\circ}-\mathrm{A}$ no art. 135 da Lei n 4737/65 (Código Eleitoral) ${ }^{11}$, dispondo:

\6º-A. Os Tribunais Regionais Eleitorais deverão, a cada eleição, expedir instruções aos Juízes Eleitorais para orientá-los na escolha dos locais de votação, de maneira a garantir acessibilidade para o eleitor com deficiência ou com mobilidade reduzida, inclusive em seu entorno e nos sistemas de transporte que lhe dão acesso.

A LBI (art. 76, $\$ 1^{\circ}$, III) também exige que os recursos de legenda, Libras e audiodescrição estejam disponíveis em pronunciamentos oficiais, na propaganda eleitoral obrigatória e debates transmitidos pelas emissoras de televisão ${ }^{12}$. Anota-se que tal medida é recomendada pelo Relatório da ONU (2011) sobre a participação das pessoas com deficiência na vida pública e política.

Aliás, ainda no incentivo ao desempenho de funções públicas, garante-se constitucionalmente a reserva de cargos e empregos públicos às pessoas com deficiência (art. 37, VIII, da CR/88). De acordo com o Decreto $\mathrm{n}^{\mathrm{o}} 3.298 / 99$ (que regulamenta a Lei no $7.853 / 89$ ), o candidato com deficiência concorrerá a todas as vagas, sendo reservado, no mínimo, o percentual de cinco por cento em face da classificação obtida (art. 5ㅇ, $\$ 2^{\circ}$ ).

Sobre a relação entre capacidade jurídica e voto, como ressaltam Dias e Junqueira (2016, p. 296), o artigo 85 da LBI, deu passo importantíssimo, inclusive conceitual, em direção à efetiva implementação da Convenção da ONU e à concretização dos direitos das pessoas com deficiência, ao expressamente afirmar que a curatela afetará tão somente os atos relacionados aos direitos de natureza patrimonial e negocial, não podendo restringir, dentre outros, o direito de voto.

Já era tempo de reconhecer que eventual necessidade de proteção patrimonial não pode implicar desnecessária limitação aos direitos existen-

${ }^{11}$ Tal dispositivo foi inspirado no art. 3o, I, do Programa de Acessibilidade da Justiça Eleitoral (Resolução TSE no $23.381 / 12$ ) o qual dispõe: “Objetivando a plena acessibilidade nos locais de votação, os Tribunais Regionais Eleitorais, em conjunto com as respectivas Zonas Eleitorais, elaborarão plano de ação destinado a: I - expedir, a cada eleição, instruções aos Juízes Eleitorais, para orientá-los na escolha dos locais de votação de mais fácil acesso ao eleitor com deficiência física."

${ }^{12}$ Vide, no particular, o disposto também no art. 57, parágrafo único, do Decreto no $5296 / 2004$. 
ciais do sujeito. $\mathrm{Na}$ linha da nova abordagem inaugurada pela Convenção da ONU, sobre a capacidade jurídica das pessoas com deficiência ${ }^{13}$, enfatiza-se que a curatela é medida extraordinária (LBI, artigo 84, parágrafo $3^{\circ}$ ), que não pode lhes impor restrições indevidas em contraposição ao direito da pessoa com deficiência à tomada de decisão apoiada (LBI, artigo 84, parágrafo $2^{\circ}$ ). Com essa medida, o País também acompanha a mais recente jurisprudência de organismos internacionais de direitos humanos sobre a garantia na sua mais absoluta plenitude do direito de voto das pessoas com deficiência ${ }^{14}$.

Nesse sentido, a Lei Brasileira de Inclusão opera verdadeira mudança de paradigma, vista por Gagliano e Pamplona Filho (2016, p. 50) como uma homenagem ao princípio da dignidade da pessoa humana: a pessoa com deficiência deixou de ser genérica e aprioristicamente rotulada como incapaz, para passar a ser avaliada, em uma "perspectiva constitucional isonômica", como "dotada de plena capacidade legal, ainda que haja a necessidade de adoção de institutos assistenciais específicos, como a tomada de decisão apoiada e, extraordinariamente, a curatela, para a prática de atos na vida civil".

Importante destacar que, antes mesmo da promulgação da Lei Brasileira de Inclusão, na tentativa de equiparar oportunidades no exercício da cidadania aos eleitores e eleitoras com deficiência ou mobilidade redu-

${ }^{13}$ Com efeito, em seu artigo 12, que garante às pessoas com deficiência o gozo de capacidade jurídica em igualdade de condições com as demais pessoas em todos os aspectos da vida, a Convenção da ONU prescreve, no item 4, do referido dispositivo normativo, que os "Estados Partes assegurarão que todas as medidas relativas ao exercício da capacidade legal incluam salvaguardas apropriadas e efetivas para prevenir abusos, em conformidade com o direito internacional dos direitos humanos. Essas salvaguardas assegurarão que as medidas relativas ao exercício da capacidade legal respeitem os direitos, a vontade e as preferências da pessoa, sejam isentas de conflito de interesses e de influência indevida, sejam proporcionais e apropriadas às circunstâncias da pessoa, se apliquem pelo período mais curto possível e sejam submetidas à revisão regular por uma autoridade ou órgão judiciário competente, independente e imparcial. As salvaguardas serão proporcionais ao grau em que tais medidas afetarem os direitos e interesses da pessoa."

${ }^{14}$ No caso Alajos Kiss contra Hungria, por exemplo, a Corte Europeia de Direitos Humanos afirmou, à unanimidade, que a "supressão indiscriminada dos direitos de voto, sem uma avaliação judicial individualizada e assente apenas numa deficiência mental que carece de tutela parcial, não pode ser considerada compatível com os motivos legítimos para restringir o direito de eleger." Corte Europeia de Direitos Humanos, Alajos Kiss contra Hungria, n⿳ 38832/06, acórdão de 20 de Maio de 2010. 
zida, o Tribunal Superior Eleitoral já havia criado o Programa de Acessibilidade da Justiça Eleitoral (Resolução no 23.381/2012), que, na mesma linha do que posteriormente seria preconizado também pela LBI, garante acessibilidade nos procedimentos, instalações e materiais para votação ${ }^{15}$.

Tendo como objetivo a implantação gradual de medidas que removam barreiras físicas, arquitetônicas e de comunicação, o objetivo do Programa é promover o acesso, amplo e irrestrito, com segurança e autonomia, às pessoas com deficiência ou com mobilidade reduzida no processo eleitoral.

Nesse sentido, por exemplo, o Programa estabelece que as urnas eletrônicas, além das teclas em Braille, também devem ser habilitadas com sistema de áudio, fornecendo os Tribunais Regionais Eleitorais (TREs) fones de ouvido nas seções eleitorais especiais ou, quando solicitados, por eleitor com deficiência visual. Ou ainda: os mesários devem ser orientados pelos Tribunais Eleitorais para facilitar todo o processo de adaptação à Resolução, estando previsto, inclusive, parcerias para incentivar o cadastramento de colaboradores com conhecimento em Língua Brasileira de Sinais (Libras).

Além disso, os TREs devem contar com comissão multidisciplinar destinada a elaborar plano de ação contemplando as medidas previstas na Resolução, acompanhar as atividades realizadas, e encaminhar o respectivo relatório ao TSE até o dia 20 de dezembro de cada ano.

Quanto à acessibilidade digital, os sites dos TREs devem ser adaptados a todos os tipos de deficiência, para garantia do pleno acesso, e disponibilizar a legislação eleitoral também em áudio.

Releva notar que, em seu $1^{\circ}$ Relatório Nacional sobre o cumprimento das disposições da Convenção da ONU sobre os Direitos das Pessoas com Deficiência, o Brasil admite que ainda não garante a participação política das pessoas com deficiência em toda a sua plenitude devido a obstáculos como a falta de acesso a informações sobre as plataformas políticas e as propostas dos candidatos e candidatas. O Relatório também registra que, por diversas vezes, as campanhas eleitorais brasileiras não são apresentadas em formato acessível, principalmente no que diz respeito aos sítios eletrônicos e ao material impresso. Informa, também, que, no interior

${ }^{15}$ Vide art. 76, §19丷, I da LBI. 
do País, é ainda mais difícil o acesso aos colégios eleitorais, o que dificulta a participação de pessoas com mobilidade reduzida ${ }^{16}$.

Em suas observações finais sobre o referido relatório brasileiro, de $1^{\circ}$ de setembro de 2015, o Comitê da ONU que supervisiona a implementação da Convenção pelos países que a ratificaram, externou preocupação com a discriminação sofrida pelas pessoas com deficiência no exercício do seu direito de voto, especialmente em razão de interdição e restrições a sua capacidade jurídica, da falta de acessibilidade em muitos locais de votação, e da indisponibilidade das informações sobre as eleições em todos os formatos acessíveis ${ }^{17}$.

\section{Recomendações e Boas Práticas}

Em apoio aos esforços nacionais para a consecução dos seus objetivos, a Convenção da ONU destaca a importância também da cooperação internacional entre os países, e de parcerias com organizações internacionais e com a sociedade civil, especialmente, com entidades de pessoas com deficiência ${ }^{18}$. Dentre outras medidas, a Convenção da ONU prevê, no particular, o apoio à capacitação, inclusive por meio do compartilhamento de informações, experiências, programas de treinamento e melhores práticas ${ }^{19}$.

No mesmo sentido, ao prescrever, por exemplo, a obrigatoriedade da acessibilidade nos sítios da internet, a LBI, em seu art. 63, também menciona as melhores práticas e diretrizes de acessibilidade adotadas internacionalmente como medidas a serem consideradas na garantia de acesso das pessoas com deficiência à informação e à comunicação.

A seguir, listamos algumas dessas "melhores práticas e políticas inovadoras" em diferentes países, as quais têm proporcionado às pessoas com deficiência maior participação na vida pública e política. Na seleção, lançamos mão de Estudo Temático da ONU sobre a participação das pessoas com deficiência na vida pública e política, do Relatório Anual de 2015

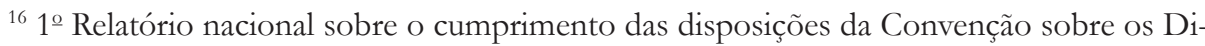
reitos das Pessoas com Deficiência. Disponível em: <http://www.sdh.gov.br/assuntos/ pessoa-com-deficiencia/dados-estatisticos/relatorio-de-monitoramento-da-convencao $>$. Acesso em 21 jan. 2016.

17 Disponível em: <https://documents-dds-ny.un.org/doc/UNDOC/GEN/G15/220/75/ PDF/G1522075.pdf?OpenElement>. Acesso em 31 ago. 2017.

${ }^{18}$ Vide art. 32, 1, da CDPD.

${ }^{19}$ Vide art. 32, 1, b, da CDPD.

Resenha Eleitoral (Florianópolis), v. 21, n. 1, p. 159-180, nov. 2017 
elaborado pelo Zero Project ${ }^{20}$ e do Relatório do Instituto Nacional Democrata (IND) em parceria com a Fundação Internacional para Sistemas Eleitorais (IFES) ${ }^{21}$ :

\begin{tabular}{|l|l|l|}
\hline $\begin{array}{l}\text { PRÁTICA/POLÍTICA } \\
\text { INOVADORAS }\end{array}$ & \multicolumn{1}{|c|}{ PAÍS } & \multicolumn{1}{c|}{ DESCRIÇÃO } \\
\hline $\begin{array}{l}\text { Reserva de cargo eletivo no } \\
\text { poder executivo para pessoas } \\
\text { com deficiência }\end{array}$ & Uganda & $\begin{array}{l}\text { Cada vila, subcondado, condado e conselho do } \\
\text { distrito deve reservar, pelo menos, um cargo } \\
\text { eletivo destinado à pessoa com deficiência. }\end{array}$ \\
\hline $\begin{array}{l}\text { Acesso igualitário aos meios } \\
\text { de divulgação das atividades } \\
\text { parlamentares }\end{array}$ & África do Sul & $\begin{array}{l}\text { Durante os discursos parlamentares, o país } \\
\text { disponibiliza intérprete de sinais, unidade de } \\
\text { produção de material em Braile e tela com } \\
\text { texto eletrônico. }\end{array}$ \\
\hline $\begin{array}{l}\text { Direito de voto e capacidade } \\
\text { jurídica }\end{array}$ & Croácia e & $\begin{array}{l}\text { Ampla campanha de sensibilização da opinião } \\
\text { pública, mediante oficinas e informações } \\
\text { transmitidas pela televisão e rádio sobre } \\
\text { direitos das pessoas com deficiência. Os } \\
\text { países passaram a admitir como eleitores as } \\
\text { pessoas com deficiência intelectual. }\end{array}$ \\
\hline E-voting & Austrália & $\begin{array}{l}\text { Criou-se um software que auxilia o processo } \\
\text { de votação dos deficientes visuais, dos } \\
\text { analfabetos, daqueles que não sabem ler a } \\
\text { língua inglesa. O software foi disponibilizado } \\
\text { nas seções oficiais de votação e também nos } \\
\text { centros oficiais de votação antecipada. }\end{array}$ \\
\hline $\begin{array}{l}\text { Fundo de financiamento } \\
\text { eleitoral }\end{array}$ & Reino Unido & $\begin{array}{l}\text { Suporte financeiro destinado às pessoas com } \\
\text { deficiência que ocuparem mandatos políticos } \\
\text { ou que lançarem candidatura política. }\end{array}$ \\
\hline
\end{tabular}

20 Zero Project é uma iniciativa internacional da Fundação Essl, da Áustria, com foco na garantia e promoção dos direitos das pessoas com deficiência em âmbito global. Seu principal propósito é o de oferecer plataforma de soluções práticas inovadoras e eficazes para efetivação dos direitos das pessoas com deficiência. Relatório anual de 2015: Vida Independente e Participação Política. Disponível em < http://zeroproject.org/downloads/\#toggle-id-26>. Acesso em 20 jan. 2015

${ }^{21}$ A Fundação Internacional para Sistemas Eleitorais (IFES) é uma organização internacional, sem fins lucrativos, que presta assistência e apoio às eleições nas democracias novas e emergentes. Fundação Internacional Para Sistemas Eleitorais (IFES). Relatório em parceria com o Instituto Nacional Democrata (IND). Igualdade de Acesso: Como incluir as pessoas com deficiência nas eleições e nos processos políticos, 2014. Disponível em: <http://www.ifes.org/news/2014-annual-report>. Acesso em 12 jan. 2016. 


\begin{tabular}{|l|l|l|}
\hline $\begin{array}{c}\text { PRÁTICA/POLÍTICA } \\
\text { INOVADORAS }\end{array}$ & \multicolumn{1}{|c|}{ PAÍS } & \multicolumn{1}{c|}{ DESCRIÇÃO } \\
\hline Votação por telefone & Nova Zelândia & $\begin{array}{l}\text { Desde 2014, a Nova Zelândia tem utilizado } \\
\text { o sistema de votação por telefone para as } \\
\text { pessoas com deficiência visual ou outro tipo } \\
\text { de deficiência que as impeçam de marcar o } \\
\text { voto na célula. }\end{array}$ \\
\hline $\begin{array}{l}\text { Semana das Pessoas com } \\
\text { Deficiência }\end{array}$ & Filipinas & $\begin{array}{l}\text { Anualmente, realiza-se a "Semana das Pessoas } \\
\text { com Deficiência", campanha nacional de } \\
\text { sensibilização a favor da participação política } \\
\text { das pessoas com deficiência. }\end{array}$ \\
\hline Código de Conduta & Serra Leoa & $\begin{array}{l}\text { Código de conduta eleitoral destinado aos } \\
\text { partidos políticos, sob o risco de sanção em } \\
\text { caso de descumprimento. O documento tenta } \\
\text { promover um ambiente eleitoral sem violência } \\
\text { e intimidação, incentivando a participação } \\
\text { das mulheres e outros grupos socialmente } \\
\text { marginalizados. }\end{array}$ \\
\hline
\end{tabular}

Quadro 1 - Melhores práticas e políticas inovadoras

Fonte: Dias e Junqueira (2016)

Com base em recomendações da ONU e da Agência da União Europeia para Direitos Fundamentais - FRA (2014), enumeramos algumas medidas que, a partir da experiência internacional, também o Brasil, na implementação da Convenção da ONU e da LBI, pode tomar como referência no louvável e necessário esforço de maior inclusão das pessoas com deficiência e efetivação do seu direito de participação na vida pública e política:

\begin{tabular}{|l|l|}
\hline RECOMENDAÇÃO & DESCRIÇÃO \\
\hline $\begin{array}{l}\text { Aumentar a conscientização } \\
\text { social e emancipar as } \\
\text { pessoas com deficiência }\end{array}$ & $\begin{array}{l}\text { Segundo as Nações Unidas, a disseminação de informação } \\
\text { e educação é o instrumento mais efetivo para se erradicar } \\
\text { estereótipos, para se garantir a emancipação política das pessoas } \\
\text { com deficiência e suprimir as barreiras de acessibilidade. } \\
\text { Um relatório preparado pelo Centro de Vida Independente de } \\
\text { Hanoi (Vietnã) detectou que, dentre as 50 famílias de pessoas } \\
\text { com deficiência entrevistadas, metade acredita que as pessoas } \\
\text { com deficiência não devem votar, para não se preocuparem com } \\
\text { questões políticas. Como também aponta o relatório, a razão mais } \\
\text { comum das pessoas com deficiência não terem seus documentos } \\
\text { nacionais é o fato de seus familiares não acharem necessário. }\end{array}$ \\
\hline
\end{tabular}




\begin{tabular}{|c|c|}
\hline RECOMENDAÇÃO & DESCRIÇÃO \\
\hline $\begin{array}{l}\text { Participação no desenvolvi- } \\
\text { mento de políticas }\end{array}$ & $\begin{array}{l}\text { Segundo a FRA, as organizações representativas e as próprias } \\
\text { pessoas com deficiência devem participar ativamente na formulação, } \\
\text { no monitoramento e na avaliação de políticas e medidas destinadas a } \\
\text { promover e proteger os seus direitos políticos. } \\
\text { As pessoas com deficiência não devem ser apenas objeto de } \\
\text { programas de ajuda, devem também participar ativamente como } \\
\text { líderes de seus respectivos governos. }\end{array}$ \\
\hline $\begin{array}{l}\text { Eliminação dos obstáculos } \\
\text { administrativos à participa- } \\
\text { ção política }\end{array}$ & $\begin{array}{l}\text { Segundo a FRA, na maioria dos países subsistem obstáculos } \\
\text { jurídicos e administrativos que continuam a impedir que algumas } \\
\text { pessoas com deficiência denunciem lesão ou ameaça de lesão de } \\
\text { seus direitos políticos. São exemplos de obstáculos: } \\
\text { - processos administrativos inacessíveis e complexos, suscetíveis } \\
\text { de privar as pessoas com deficiência do direito de voto; ou seja, } \\
\text { processos que na prática podem privar as pessoas com deficiência } \\
\text { dos seus direitos; } \\
\text { - dificuldades no acesso aos mecanismos de apresentação de } \\
\text { requerimentos nos casos em que as pessoas com deficiência } \\
\text { enfrentam problemas no exercício do direito de voto. }\end{array}$ \\
\hline $\begin{array}{l}\text { Dissociação entre voto e } \\
\text { capacidade jurídica }\end{array}$ & $\begin{array}{l}\text { O Comitê sobre os Direitos das Pessoas com Deficiência } \\
\text { recomendou à Espanha e à Tunísia revisarem suas legislações, } \\
\text { de forma a conceder o direito de voto e de participação na vida } \\
\text { pública às pessoas com deficiência intelectual ou psicossocial sob tutela } \\
\text { ou curatela. (CDPD/C/TUN/1) e (CDPD/C/TUN/CO/1 par. 35). }\end{array}$ \\
\hline $\begin{array}{l}\text { Recolha de dados para me- } \\
\text { dir a participação política } \\
\text { das pessoas com deficiência }\end{array}$ & $\begin{array}{l}\text { Segundo Relatório mundial da ONU sobre a deficiência, ainda não } \\
\text { é possível avaliar com rigor a situação existente no que respeita à } \\
\text { participação política das pessoas com deficiência, devido à falta de } \\
\text { dados fiáveis e comparáveis. Não há identificação clara a respeito dos } \\
\text { tipos de barreiras enfrentados pelas pessoas com deficiência em sua } \\
\text { participação política, bem como há uma imprecisão na identificação } \\
\text { dos suportes necessários que garantirão a acessibilidade eleitoral. }\end{array}$ \\
\hline $\begin{array}{l}\text { Disseminação de boas prá- } \\
\text { ticas }\end{array}$ & $\begin{array}{l}\text { O artigo 32, da CDPD, requer cooperação internacional mediante } \\
\text { troca e partilha de informações sobre experiências e boas práticas. } \\
\text { Isso inclui assegurar acessibilidade aos programas de eleições } \\
\text { inclusivas para que as pessoas com deficiência participem. Além } \\
\text { disso, bons exemplos e materiais educativos devem ser compilados } \\
\text { e divulgados em todo o mundo, principalmente por intermédio de } \\
\text { ferramentas eletrônicas acessíveis. }\end{array}$ \\
\hline $\begin{array}{l}\text { Aprimorar a acessibilidade } \\
\text { ao voto }\end{array}$ & $\begin{array}{l}\text { Segundo a Conferência dos Estados Partes na Convenção sobre os } \\
\text { direitos das pessoas com deficiência (ONU, 2011), devem ser ga- } \\
\text { rantidas cabines de votação que permitam o acesso em cadeiras de } \\
\text { rodas, iluminação adequada, lugares de estacionamento acessíveis, } \\
\text { espaços com portas suficientemente largas, formas alternativas de } \\
\text { voto (voto eletrônico, estações móveis de voto, voto por corres- } \\
\text { pondência, votação por procuração e votação antecipada). }\end{array}$ \\
\hline
\end{tabular}

Quadro 2 - Medidas para a maior inclusão das pessoas com deficiência e a efetivação do seu direito de participação na vida pública e política.

Fonte: Elaborado pelos autores. 


\section{Conclusão}

Em sua investigação historiográfica a respeito dos elementos que marcam a tradição republicana, Pocock (2013, p. 28) rememora o contexto do "bumanismo civico", na Florença do Renascimento, assinalando que esse "estilo de pensamento" considera que o "desenvolvimento do indivíduo, em direção a sua própria realização, só é possivel quando esse indivíduo age como cidadão, ou seja, como um participante consciente e autônomo de uma comunidade política que autonomamente toma as suas decisões, a pólis, ou república."

A ideia, que era a de que a república, sob pena de se corromper, não pode subsistir sem a participação, sem a parceria de todos os seus cidadãos na busca do bem geral, ainda nas sociedades atuais parece-nos central. Não por outro motivo, temos que a participação política é elemento crucial e precípuo para a efetivação também dos direitos das pessoas com deficiência, e a consecução dos objetivos da Convenção da ONU.

Ao participarem da tomada de decisões políticas, especialmente sobre os assuntos que mais diretamente lhes dizem respeito, as pessoas com deficiência criam as condições favoráveis e incidem diretamente na construção e efetivação de seus direitos fundamentais. Tal participação facilita ainda o diálogo e a cooperação com governos, demais poderes e atores sociais. Como diz o lema de seu movimento internacional, "nada sobre as pessoas com deficiência, sem as pessoas com deficiência".

Não obstante as normas de proteção e promoção de acessibilidade eleitoral sejam mais um importante avanço, a efetivação do direito de participação das pessoas com deficiência reclama o planejamento e a execução de políticas públicas intersetoriais (que viabilizem a universalização do acesso a bens e serviços públicos), educação em direitos humanos (a fim de que as pessoas com deficiência se reconheçam como titulares ou sujeitos de direitos), e o desenvolvimento de programas de apoio à participação na sociedade civil. (REICHER; ATALLA, 2015).

\section{Referências}

AGÊNCIA DA UNIÃO EUROPEIA PARA OS DIREITOS FUNDAMENTAIS (FRA). $\mathbf{O}$ direito à participação política das pessoas com deficiência, 2014. 
ALVIM, Frederico; DIAS, Joelson. A Lei Brasileira de Inclusão e a efetivação do direito à participação política das pessoas com deficiência. Impactos do Estatuto da Pessoa com Deficiência no ordenamento brasileiro. Editora Jus Podivm. No prelo.

ANDRIOLI, A.I. A democracia Direita em Rousseau. Revista Espaço Acadêmico, 03/2003. In: ROUSSEAU, Jean-Jacques Rousseau. O Contrato Social. São Paulo: Formar, 1980.

BASTOS, Celso Ribeiro; MARTINS, Ives Gandra. Comentários à Constituição do Brasil - Promulgada em 5 de outubro de 1988, p. 13. Disponível em: <http://www.pessoacomdeficiencia.gov.br/app/sites/ default/files/ publicacoes/a-protecao-constitucional-das-pessoas-com-deficiencia_0.pdf $>$. Acesso em: 1 jan. 2016.

CALDAS, Roberto. Obrigações Gerais do art. $4^{\circ}$ da Convenção da ONU sobre os direitos das pessoas com deficiência. In: DIAS, Joelson; GUGEL, Maria Aparecida, outros (Organ.) Convenção sobre os direitos das pessoas com deficiência: Novos comentários. Presidência da República. Brasília: 2014. Disponível em: <http://www.pessoacomdeficiencia.gov.br/app/ sites/default/files/publicacoes/convencao-sdpcd-novos-comentarios.pdf>. Acesso em: 27 ago. 2017

DAHL, Robert. Sobre a democracia. Brasília: UNB, 2009.

. Sobre a democracia. Brasília: UNB, 2009. In: ALVIM, Frederico; DIAS, Joelson. A Lei Brasileira de Inclusão e a efetivação do direito à participação política das pessoas com deficiência. Impactos do Estatuo da Pessoa com Deficiência no ordenamento brasileiro. Editora Jus Podivm. No prelo.

DALLARI, Dalmo de Abreu. O que é participação política. São Paulo: Brasiliense, 2004. In: VOLPATO, R. A participação popular como direito fundamental em um estado democrático de direito. Disponível em: $<$ http://jus.com.br/artigos/33782/a-participacao-popular-como-direito-fundamental-em-um-estado-democratico-de-direito\#ixzz3uofXH37c > . Acesso em: 12 dez. 2015.

DIAS, Joelson; JUNQUEIRA, Ana Luísa Cellular. A lei brasileira de inclusão e o direito das pessoas com deficiência à participação na vida pública e política. In: LEITE, Flávia Piva Almeida; RIBEIRO, Lauro Luiz Gomes; COSTA FILHO, Waldir Macieira da. Comentários ao Estatuto da Pessoa com Deficiência. São Paulo: Saraiva, 2016. 


\section{FUNDAÇÃO INTERNACIONAL PARA SISTEMAS ELEITORAIS} (IFES). Relatório em parceria com o Instituto Nacional Democrata (IND). Igualdade de Acesso: Como incluir as pessoas com deficiência nas eleições e nos processos políticos, 2014. Disponível em: <http://www.ifes.org/news/ 2014-annual-report>. Acesso em: 12 jan.2016.

GAGLIANO, Pablo Stolze; PAMPLONA FILHO, Rodolfo. Manual de Direito Civil. São Paulo: Saraiva, 2016.In: ALVIM, Frederico; DIAS, Joelson.

A Lei Brasileira de Inclusão e a efetivação do direito à participação política das pessoas com deficiência. Impactos do Estatuto da Pessoa com Deficiência no ordenamento brasileiro. Editora Jus Podivm. No prelo.

HABERMAS, Jürgen. A inclusão do outro: estudos de teoria política. São Paulo: Edições Loyola. 2002.

MENDES, Gilmar Ferreira; BRANCO, Paulo Gustavo Gonet. Curso de Direito Constitucional. São Paulo: Saraiva, 2011, p. 1205.

NAÇÕES UNIDAS. Oficina do Alto Comissariado das Nações Unidas para os Direitos Humanos: Estudo temático sobre a participação das pessoas com deficiência na vida política e pública, 2011.

. Organização Mundial de Saúde. Relatório mundial da ONU sobre a deficiência, 2011

PATEMAN, Carole. Participação e teoria democrática. Rio de Janeiro: Paz e Terra, 1992. In: ALVIM, Frederico; DIAS, Joelson. A Lei Brasileira de Inclusão e a efetivação do direito à participação política das pessoas com deficiência. Impactos do Estatuto da Pessoa com Deficiência no ordenamento brasileiro. Editora Jus Podivm. No prelo.

POCOCK, John. Cidadania, Historiografia e Res Publica. Contextos do Pensamento Político. Coimbra: Almedina, 2013.

RAWLS, John. Teoria de la justicia. Madrid: Fondo de Cultura Económica, 1995.

REICHER, Stella; ATALLA, Regina. A Convenção da ONU sobre os Direitos das Pessoas com Deficiência - Status de Implementação nos países do G20. Disponível em: <http://www.kas.de/wf/doc/4434-1442-5-30. pdf>. Acesso em: 22 dez. 2015.

REQUIÃO, M. Estatuto da Pessoa com Deficiência altera regime civil das incapacidades. Disponível em: <http:/ /www.conjur.com.br/ 2015-jul-20/estatuto-pessoa-deficiencia-altera-regime-incapacidades $>$. Acesso em: 20 dez. 2015. 
ROCHA, Carmen Lúcia. O processo eleitoral como instrumento para a democracia. Disponível em: <https://www.tre-sc.jus.br/site/resenha-eleitoral/edicoes-impressas/integra/2012/06/o-processo-eleitoral-como-instrumento-para-a-democracia/index 49ea.html?no_cache $=1 \& \mathrm{cHash}=\mathrm{ff5} 61 \mathrm{~b} 25 \mathrm{fe}-$ 4f395adf3f064a96fe90a1>. Acesso em: 20 dez. 2015.

SEN, Amartya. A ideia de justiça. São Paulo: Companhia das Letras, 2011. SILVA, José Afonso da. Curso de direito constitucional positivo. 19. ed. rev. e atual. São Paulo: Malheiros Editores, 2001.

URROZ, Juan Calanchini. Gobernabilidad: legitimidad - eficacia efectividad estabilidad - participación política. In: CALANCHINI, Juan J (coord.). Lecturas de Ciencia Política. Tomo II. Montevideo: 2011. In: ALVIM, Frederico; DIAS, Joelson. A Lei Brasileira de Inclusão e a efetivação do direito à participação política das pessoas com deficiência. Impactos do Estatuto da Pessoa com Deficiência no ordenamento brasileiro. Editora Jus Podivm. No prelo.

ZERO PROJECT. Relatório Anual de 2015: Vida Independente e Participação Política. Disponível em: <http://zeroproject.org/downloads/\#toggle-id-26>. Acesso em: 20 jan. 2016.

Joelson Dias - Mestre em Direito pela Universidade de Harvard. Ex-Ministro substituto do Tribunal Superior Eleitoral (TSE). Advogado e sócio do escritório Barbosa e Dias Advogados Associados (Brasília-DF). Vice-Presidente da Comissão Nacional dos Direitos das Pessoas com Deficiência do Conselho Federal da Ordem dos Advogados do Brasil (OAB).

Ana Luísa Cellular Junqueira - Doutoranda pela Universidade de Coimbra. Mestre em Direitos Humanos pela Universidade do Minho. Advogada e parceira do escritório Barbosa e Dias Advogados Associados (Brasília-DF). 